\title{
Ten years of biosimilar recombinant human growth hormone in Europe
}

\author{
This article was published in the following Dove Press journal: \\ Drug Design, Development and Therapy \\ 16 May 2017 \\ Number of times this article has been viewed
}

\author{
Paul Saenger \\ Division of Pediatric Endocrinology, \\ Department of Pediatrics, Winthrop \\ University Hospital, Mineola, NY, USA
}

\begin{abstract}
Recombinant human growth hormone ( $\mathrm{rhGH}$ ) has been in clinical use for more than 30 years. With the expiration of patent exclusivity for the first wave of rhGH products and other biopharmaceuticals, the opportunity emerged for the development of biosimilar medicines. A biosimilar is defined by the European Medicines Agency (EMA) as a biological medicine that is similar to another biological medicine that has already been authorized for use. The EMA led the way (well ahead of the Food and Drug Administration in the US) in developing the biosimilar concept, and the type of science-based regulatory framework required to ensure high-quality, safe, and effective biosimilar medicines; the provisions for approval of biosimilars have been in place in Europe since 2005. Under these provisions, Omnitrope ${ }^{\circledR}$ was approved by the EMA in 2006 as the world's first biosimilar medicine; 2016 therefore marks the 10th anniversary of its approval in Europe. A substantial data set, based on clinical development studies and 10 years of postapproval use, has now accumulated for biosimilar rhGH; this data set shows that the product is an effective treatment option for children who require rhGH treatment, and has a safety profile that is consistent with the rhGH class. The decade since the EMA approved biosimilar rhGH has seen the successful approval and clinical use of 20 biosimilar medicines, confirming the integrity of the scientific basis for the biosimilar concept, as well as the quality of regulatory decision-making.
\end{abstract}

Keywords: recombinant human growth hormone, Omnitrope ${ }^{\circledR}$, biosimilar

\section{Introduction}

Recombinant human growth hormone (rhGH) has been in clinical use for more than 30 years since the approval of the first product in the mid-1980s in the US. ${ }^{1,2}$ Before the development of recombinant DNA technology, GH for replacement therapy could be obtained only by extraction and purification from cadaveric human pituitary glands (Figure 1). Supply was therefore scarce, and GH replacement therapy was reserved for only the most severe cases of growth hormone deficiency (GHD). ${ }^{1}$ The advent of a plentiful supply of rhGH was an important milestone, enabling treatment of more children (and subsequently adults) with GHD and expansion of use to other indications.

With the expiration of patent exclusivity for the first wave of rhGH products and other biopharmaceuticals, the opportunity emerged for the development of biosimilar medicines. ${ }^{3,4}$ A biosimilar is defined by the European Medicines Agency (EMA) as a biological medicine that is similar to another biological medicine that has already been authorized for use. The EMA led the way in developing the biosimilar concept, and the type of science-based regulatory framework required to ensure high-quality, safe, and effective biosimilar medicines; the provisions for approval of biosimilars have 


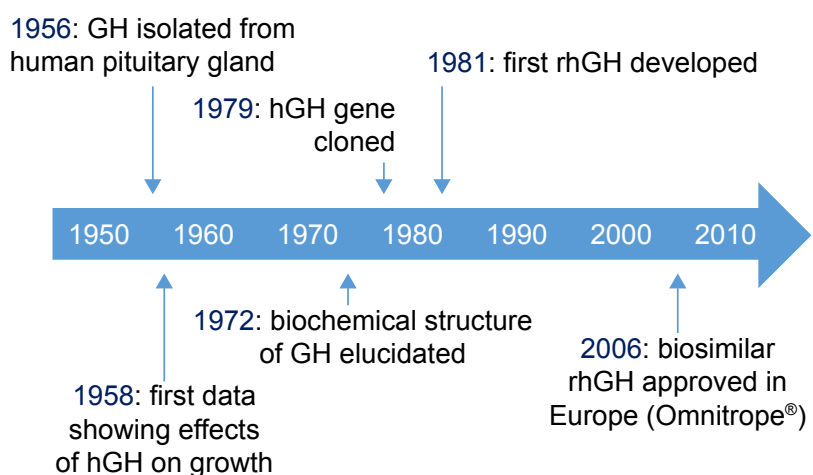

Figure I History of GH therapy.

Abbreviations: $\mathrm{GH}$, growth hormone; rhGH, recombinant human growth hormone.

been in place in Europe since 2005. ${ }^{3}$ Under these provisions, Omnitrope $^{\circledR}$ (biosimilar rhGH; Sandoz, Kundl, Austria) was approved by the EMA in 2006 as the world's first biosimilar medicine. Approvals have followed around the world, including the US (via a nonbiosimilar pathway), and the product is now available in more than 50 countries. Since launch, more than 40,000 patients have been treated with biosimilar rhGH, generating almost 107 million patient-days' experience. Continued product development in the rhGH arena has focused on delivery devices to bring additional benefits to patients, with conventional syringes and needles replaced by more user-friendly devices. ${ }^{5}$ In the case of biosimilar rhGH, a new and improved delivery device (SurePal $\left.{ }^{\mathrm{TM}}\right)$ was launched in 2013/14. SurePal ${ }^{\mathrm{TM}}$ has been specifically designed to be easy and convenient to use and to minimize drug wastage. ${ }^{6}$

The year 2016 therefore marks the 10th anniversary of the approval of biosimilar rhGH in Europe. This special themed issue provides an overview of developments during this decade. The first paper reviews the emergence of the biosimilar regulatory framework in Europe and how development of the framework was informed by the experience with biosimilar rhGH. ${ }^{7}$ It reminds us that the biosimilar framework is based on the "comparability concept" - a set of sound scientific principles that have been used for many years to assess already approved biopharmaceuticals following changes to the manufacturing process. The authors also highlight the continuing evolution of the regulatory environment for biosimilars, in recognition of technological advances and the advent of new targets for biosimilar development.

A substantial data set, based on clinical development studies and 10 years of postapproval use, has now accumulated for biosimilar rhGH. The paper by Borrás Pérez et al ${ }^{8}$ summarizes the safety experience that is now available for this medicine. There are a number of safety concerns that apply to all rhGH products, including the impact on risk of malignancies, the impact on glucose homeostasis, and the formation of antibodies to endogenous/exogenous GH. ${ }^{9,10}$ There are additional concerns that relate to a biosimilar rhGH, such as safety in indications granted on the basis of extrapolation and the impact of changing to biosimilar rhGH from other rhGH treatments. ${ }^{11}$ It is therefore reassuring that, to date, there have been no unexpected or unique adverse events related to biosimilar rhGH treatment. There have been no signals of increased risk of cancer or adverse glucose homeostasis with biosimilar rhGH, compared with the reference medicine and other rhGH products, and the immunogenicity of biosimilar rhGH is also similar to that of other products in the rhGH class. Extrapolation is a key part of the biosimilar concept, allowing for approval of a biosimilar for the same indications as the reference medicine without the need for clinical studies in each individual condition. Postapproval studies are therefore necessary to provide safety and efficacy data in extrapolated indications; again, these studies have not uncovered any unexpected or unique safety concerns with biosimilar rhGH.

The final paper in the series reviews the efficacy of biosimilar rhGH during its clinical development program and its subsequent effectiveness during 10 years of clinical use. ${ }^{12}$ Once again, the data are reassuring; the product has been proven to be effective in children with GHD and also in extrapolated indications, and concerns about the impact of changing to biosimilar rhGH from other rhGH preparations have been alleviated.

\section{Summary}

Data from clinical development studies and a decade of postapproval experience affirm that biosimilar rhGH is an effective treatment option for children who require rhGH treatment, and has a safety profile that is consistent with the rhGH class. The decade since the EMA approved biosimilar rhGH has seen the successful approval and clinical use of 20 biosimilar medicines, confirming the integrity of the scientific basis for the biosimilar concept, as well as the quality of regulatory decision-making.

\section{Acknowledgment}

Medical writing assistance was provided by Tony Reardon of Spirit Medical Communications Ltd, funded by Sandoz $\mathrm{GmbH}$.

\section{Disclosure}

PS has acted as an advisor for, and received lecture fees from, Sandoz. The author reports no other conflicts of interest in this work. 


\section{References}

1. Ayyar VS. History of growth hormone therapy. Indian J Endocrinol Metab. 2011;15(Suppl 3):S162-S165.

2. Christiansen JS, Backeljauw PF, Bidlingmaier M, et al. Growth Hormone Research Society perspective on the development of long-acting growth hormone preparations. Eur J Endocrinol. 2016;174:C1-C8.

3. Saenger P. Current status of biosimilar growth hormone. Int J Pediatr Endocrinol. 2009;2009:370329.

4. Romer T, Saenger P, Peter F, et al. Seven years of safety and efficacy of the recombinant human growth hormone Omnitrope in the treatment of growth hormone deficient children: results of a phase III study. Horm Res. 2009;72:359-369.

5. Schnabel D, Partsch CJ, Houang M, et al. Acceptance of a reusable self-injection device for recombinant human growth hormone: final data from a questionnaire-based, cross-sectional, international, multicenter, observational study in pediatric patients. Med Devices (Auckl). 2016;9: 317-324.

6. Rapaport R, Saenger P, Schmidt H, et al. Validation and ease of use of a new pen device for self-administration of recombinant human growth hormone: results from a two-center usability study. Med Devices (Auckl). 2013;6:141-146.
7. Schiestl M, Sörgel F. 10 years of biosimilars in Europe: development and evolution of the regulatory pathways. Drug Des Devel Ther. In press 2017

8. Borrás Pérez V, et al. 10 years' clinical experience with biosimilar human growth hormone (Omnitrope ${ }^{\circledR}$ ): a review of safety data. Drug Des Devel Ther. In press 2017.

9. Carel JC, Butler G. Safety of recombinant human growth hormone. Endocr Dev. 2010;18:40-54.

10. Ahangari G, Ostadali MR, Rabani A, Rashidian J, Sanati MH, Zarindast MR. Growth hormone antibodies formation in patients treated with recombinant human growth hormone. Int J Immunopathol Pharmacol. 2004;17:33-38.

11. Rashid N, Saenger P, Wu YL, et al. Switching to Omnitrope ${ }^{\circledR}$ from other recombinant human growth hormone therapies: a retrospective study in an integrated healthcare system. Biol Ther. 2014;4:27-39.

12. López-Siguero JP, et al. 10 years' clinical experience with biosimilar human growth hormone (Omnitrope $\left.{ }^{\circledR}\right)$ : a review of efficacy data. Drug Des Devel Ther. In press 2017.

\section{Publish your work in this journal}

Drug Design, Development and Therapy is an international, peerreviewed open-access journal that spans the spectrum of drug design and development through to clinical applications. Clinical outcomes, patient safety, and programs for the development and effective, safe, and sustained use of medicines are the features of the journal, which has also been accepted for indexing on PubMed Central. The manuscript management system is completely online and includes a very quick and fair peer-review system, which is all easy to use. Visit http://www.dovepress.com/testimonials.php to read real quotes from published authors.

Submit your manuscript here: http://www.dovepress.com/drug-design-development-and-therapy-journal 